\title{
To Assess the Prevalence of Dental Anxiety and Assess the Efficacy of Vibraject and to Assess Prevalence of Dental Phobia
}

\section{Swapna Sreenivasagan*, Pendum Sneha, Poornima Ravi and Krishnakumar Raja VB}

Oral and Maxillofacial Surgery, SRM Dental College, SRM University, Ramapuram, Chennai, India

\begin{abstract}
Background: Pain causes phobia. The most common reason for phobia is the injection required to achieve anesthesia which may lead to extreme anxiety. Vibraject is a novel invention that works on the principle of temporal summation of gate control theory and helps overcome the pain of injection.
\end{abstract}

Aim: To assess the prevalence of dental anxiety and to assess the efficacy of vibraject for extractions - A randomized control trial.

Subjects and Methods: A randomized controlled trial was conducted including 181 adult patients who reported to our OP for extraction with their informed consent. The dental fear was assessed based on questionnaire comprising of the Modified Dental Anxiety Scale (MDAS) and Kleinknecht's Dental Fear Survey (DFS). Split mouth technique was used. The study was undertaken by a single examiner using vibraject and conventional injection technique. Pain of injection procedure was assessed subjectively by VAS scale and was objectively confirmed by comparing their vitals with baseline vital signs during the process of injection using a finger Pulse oximeter and sphygmomanometer.

Results: $97 \%$ of the subjects are anxious towards treatment and $20 \%$ of the subjects were found to be highly anxious from the Modified dental anxiety survey. Seeing the needle and feeling of the injection has a high correlation $\left(.524^{* *} 0.530^{* *} 0.756^{* *}\right)$ with the dental anxiety scores, thus indicating that trypanophobia is a significant factor for dental fear. Female patients of were more anxious by $79 \%$ and patients with previous history of treatment $87 \%$ with negative experience were more anxious than their counter part. Out of total study subject, 27 subjects reported increased pain score while using conventional injection technique than using vibraject. The $p$ value for 2-tailed sign test shows $(p=0.00001)$ there was significant difference between two techniques. Further studies will be needed to verify this.

Keywords: Vibraject; Dental anxiety; Trypanophobia; Knuckle syndrome; Pulse oximeter

Abbreviations: MDAS: Modified Dental Anxiety Scale; DFS: Dental Fear Survey; BP: Blood Pressure; LA: Local Anesthesia; C-CLAD: Computer-Controlled Local Anesthesia Drug Delivery; HR: Heart Rate; IO: Intraosseous.

\section{Introduction}

One of the primary reasons for which patients avoid going to the dentist is fear of dental treatment [1-3]. A major component of this phobia complex is the fear of local anesthetic needles and studies have shown that several patients avoid treatment due to fear of needles [4]. Trypanophobia is associated with symptoms like increased anxiety, increased Blood Pressure (BP) - white knuckle syndrome and even vasovagal syncope. Local Anesthesia (LA) injection is, however, the commonest procedure that is performed by a dentist. Steps taken to minimize the pain and discomfort related to LA injections would benefit the patient and relax them for the duration of the procedure. Various novel techniques are being practiced to alleviate the anxiety associated with trypanophobia including Computer-Controlled Local Anesthesia Drug Delivery (CLAD); STA; Wand; TENS, etc. However, these systems are extremely expensive and are not easily available. The Vibraject is one such device designed to minimize the pain of local anesthetic injection. Vibraject works on the principle of gate control where the impulses of vibration are facilitated compared to the pain impulses that are transmitted by the smaller diameter neuronal fibres [5]. Although few studies have compared the vibraject with conventional injections, their results have been inconclusive. The aim of the current study was to assess the cause of dental anxiety and evaluate the pain perception associated with vibraject injection as opposed to the conventional injection technique.

\section{Materials and Methods}

\section{Study design}

A randomized controlled trial was conducted at our institute including all the adult patients who reported to our institute for extraction of teeth between October-December 2016 with their informed consent. The study was carried out in two parts with the first part involving the assessment of dental anxiety and the second part of the study involved the comparison of the conventional injection method painless injection method using Vibraject. Total number of 200 were enrolled in the study however only 181 patients were willing to participate in the first part of the study. The first part of the study involved evaluation of the prevalence of dental anxiety in patients undergoing dental extraction. All the patients were given the MDAS (5 questions) (Figure 1) [2] and Kleinknecht's DFS (20 questions under three categories avoidance, physiological stimuli and fear of specific stimuli) (Figure 2) [3] in their local language to assess the dental anxiety. Out of 181 patients 50 patients needed multiple extractions and were enrolled in the second part of the study. Out of the 50 patients only

*Corresponding author: Swapna Sreenivasagan, Biomedica Engineering, SRM Dental College, Bharathi Salai, SRM University, Ramapuram, Chennai, Tamil Nadu, 600089, India, Tel: 919965557487; E-mail: swapnasreenivasagan@gmail.com

Received April 29, 2018; Accepted May 30, 2018; Published June 04, 2018

Citation: Sreenivasagan S, Sneha P, Ravi P, Raja VBK (2018) To assess the Prevalence of Dental Anxiety and Assess the Efficacy of Vibraject and to assess prevalence of Dental Phobia. Dentistry 8: 491. doi:10.4172/2161-1122.1000491

Copyright: () 2018 Sreenivasagan S, et al. This is an open-access article distributed under the terms of the Creative Commons Attribution License, which permits unrestricted use, distribution, and reproduction in any medium, provided the original author and source are credited. 


\section{Modified Dental Anxiety Scale}

CAN YOU TELL US HOW ANXIOUS YOU GET, IF AT ALL, WITH YOUR DENTAL VISIT?

PLEASE INDICATE BY INSERTING ' $X$ ' IN THE APPROPRIATE BOX

1. If you went to your Dentist for TREATMENT TOMORROW, how would you feel?

$\begin{array}{lllll}\text { Not } & \text { Slightly } & \text { Fairly } & \text { Very } & \text { Extremely } \\ \text { Anxious } \square & \text { Anxious } \square & \text { Anxious } \square & \text { Anxious } \square & \text { Anxious }\end{array}$

1. If you were sitting in the WATING ROOM (waiting for treatment), how would you feel?

Not Slightly Fairly Very $\square$ Extremely

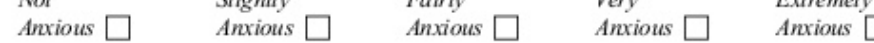

1. If you were about to have a TOOTH DRILLED, how would you feel?

$\begin{array}{lllll}\text { Not } & \text { Slightly } & \text { Fairly } & \text { Very } & \text { Extremely } \\ \text { Anxious } \square & \text { Anxious } \square & \text { Anxious } \square & \text { Anxious } \square & \text { Anxious } \square\end{array}$

1. If you were about to have your TEETH SCALED AND POLISHED, how would you feel?

$\begin{array}{lllll}\text { Not } & \text { Slightly } & \text { Fairly } & \text { Very } & \text { Extremely } \\ \text { Anxious } \square & \text { Anxious } \square & \text { Anxious } \square & \text { Anxious } \square & \text { Anxious } \square\end{array}$

1. If you were about to have a LOCALANAESTHETIC INJECTION in your gum, above an upper back tooth, how would you feel?

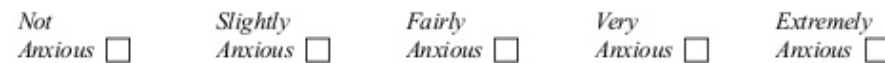

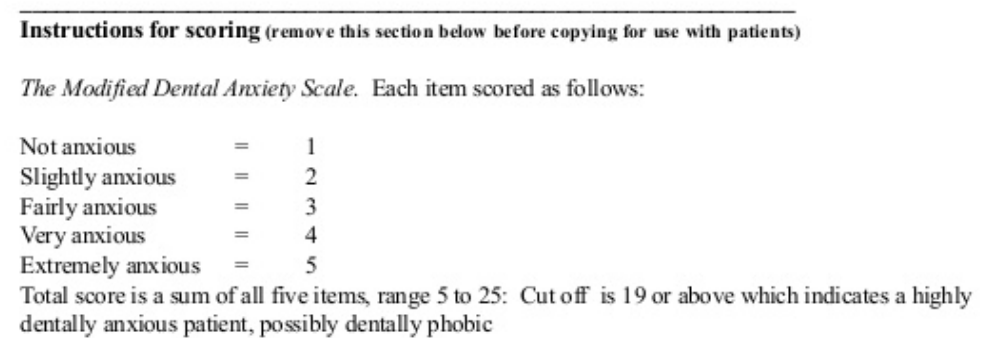

Figure 1: Modified dental anxiety scale.

31 patients participated in the study. The rest of the 19 patients were excluded from the study based on our exclusion criteria.

\section{Inclusion criteria:}

- Patients above 18 years of age

- Patients undergoing multiple extractions in different quadrants of the same jaw

\section{Exclusion criteria:}

- Patients with medical co morbidities with unstable cardiac status

- Single tooth extractions

- Multiple extractions of one side of the jaw

\section{Procedure}

Prior to the procedure, patient's demographic details were recorded. A split mouth study was conducted after recording the baseline vitals (T0) (BP; Pulse) using a sphygmomanometer and a finger Pulse oximeter. 2\% Lignocaine with 1 in 80000 Adrenaline was used for injection (Local infiltration/nerve block as deemed necessary for the case). The LA was administered by a single operator in all the patients on both the sides. In the study half, vibraject device was clipped onto the regular $2.5 \mathrm{ml}$ disposable syringe with 24 gauge needle while on the control side LA was administered using conventional Dispovan (disposable 2.5 cc syringe with 24 gauge needle). Subjective pain evaluation was done using VAS score and recorded at the time of injection. Objective assessment was obtained by evaluating the vital signs during (T1) the injection, during the extraction (T2) and these were compared with the baseline parameters to assess the patient's pain level.

\section{Statistical analysis}

The raw data was tabulated using excel sheet. Frequency distribution was used for the questionnaire. Statistical Analysis was done using correlation test and test for dispersion for the comparison between conventional injection technique and injection technique with vibraject. Levene's Test for Equality of Variances was used to assess the statistical significance for the hypothesis that use of vibraject eliminates 
Citation: Sreenivasagan S, Sneha P, Ravi P, Raja VBK (2018) To assess the Prevalence of Dental Anxiety and Assess the Efficacy of Vibraject and to assess prevalence of Dental Phobia. Dentistry 8: 491. doi:10.4172/2161-1122.1000491

\section{Dental Fear Survey Questions}

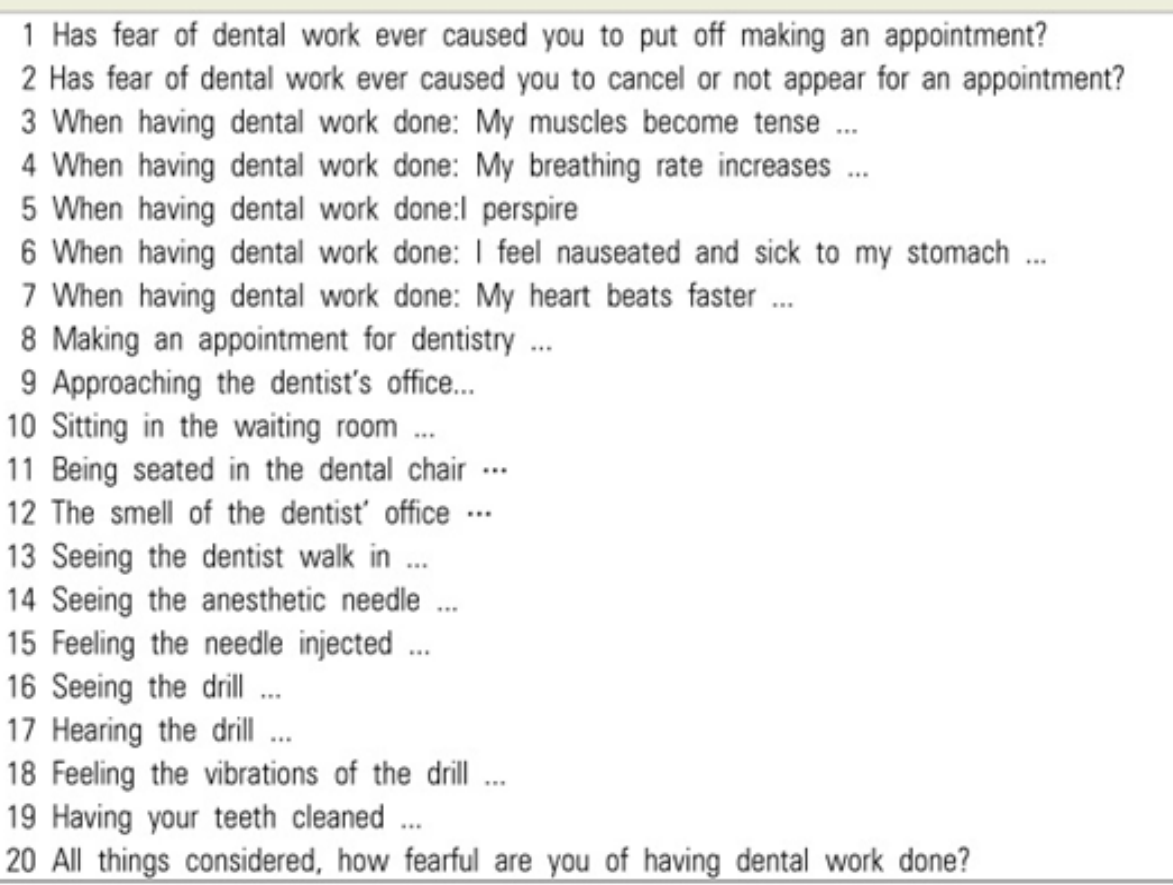

Figure 2: Dental fear survey questions.

or reduces pain sensation compared to the conventional injection techniques.

\section{Results}

181 patients voluntarily took part in the study that was targeted to assess the prevalence of dental anxiety amongst the general population. 127 were male patients and the rest of them were female patients. $97 \%$ of the patients were scored to be anxious about the procedure. $20 \%$ of which was highly anxious from the DFS. The assessment of both the questionnaire demonstrated that the female patients of were more anxious by $79 \%$ compared to the male counterparts. Apart from this patients with previous history of treatment $87 \%$ with negative experience were more anxious than their counter parts. Evaluation of the cause of anxiety demonstrated that the injection of anesthetic provoked more anxiety (38.3\% highly anxious) (Table 2 ). High correlation score with overall dental anxiety score $\left(.524^{* *} 0.530{ }^{* *} 0.756^{* *}\right)$ followed by the anticipation of the use of rotary instruments. From the DFS, $27.2 \%$ have fear on seeing the needle and $38.3 \%$ on feeling the needle (Tables 1 and 2), this was correlating with the MDAS which revealed that 36.7 $\%$ patients were anxious and has trypanophobia .The primary cause of fear with the use of injection was the anticipation of pain due to needle prick (Tables 3 and 4).

31 patients gave their voluntary consent for participating in the second part of the study that aimed at assessing the efficacy of vibraject aided injection with the conventional injection technique. Out of total study subject, 27 (87\%) subjects reported increased pain score (4.2 average VAS score) while using conventional injection technique than using vibraject (1.7 average VAS score) (Table 5). The $p$ value for 2 -tailed sign test shows $(\mathrm{p}=0.00001)$ there was significant difference between two techniques. Vibraject has significantly reduced pain both

\begin{tabular}{|c|c|c|c|c|}
\hline \multicolumn{5}{|c|}{ ON SEEING THE NEEDLE } \\
\hline Valid & Frequency & Percent & Valid percent & Cumulative percent \\
\hline 1 & 22 & 12.2 & 12.2 & 12.2 \\
\hline 2 & 31 & 17.2 & 17.2 & 29.4 \\
\hline 3 & 39 & 21.7 & 21.7 & 51.1 \\
\hline 4 & 39 & 21.7 & 21.7 & 72.8 \\
\hline 5 & 49 & 27.2 & 27.2 & 100.0 \\
\hline Total & 180 & 100.0 & 100.0 & - \\
\hline
\end{tabular}

Table 1: Frequency distribution for the questionnaire - Dental fear survey.

\begin{tabular}{|c|c|c|c|c|}
\hline \multicolumn{5}{|c|}{ ON FEELING THE INJECTION } \\
\hline Valid & Frequency & Percent & Valid percent & Cumulative percent \\
\hline 1 & 13 & 7.2 & 7.2 & 7.2 \\
\hline 2 & 30 & 16.7 & 16.7 & 23.9 \\
\hline 3 & 26 & 14.4 & 14.4 & 38.3 \\
\hline 4 & 42 & 23.3 & 23.3 & 61.7 \\
\hline 5 & 69 & 38.3 & 38.3 & 100.0 \\
\hline Total & 180 & 100.0 & 100.0 & - \\
\hline
\end{tabular}

Table 2: Frequency distribution for the questionnaire - Dental fear survey.

\begin{tabular}{|c|c|c|c|c|}
\hline \multicolumn{5}{|c|}{ LOCAL ANAESTHETIC INJECTION } \\
\hline Valid & Frequency & Percent & Valid percent & Cumulative percent \\
\hline 1 & 15 & 8.3 & 8.3 & 8.3 \\
\hline 2 & 22 & 12.2 & 12.2 & 20.6 \\
\hline 3 & 26 & 14.4 & 14.4 & 35 \\
\hline 4 & 51 & 28.3 & 28.3 & 63.3 \\
\hline 5 & 66 & 36.7 & 36.7 & 100.0 \\
\hline Total & 180 & 100.0 & 100.0 & - \\
\hline
\end{tabular}

Table 3: Frequency distribution for the questionnaire - Modified dental anxiety survey. 
Citation: Sreenivasagan S, Sneha P, Ravi P, Raja VBK (2018) To assess the Prevalence of Dental Anxiety and Assess the Efficacy of Vibraject and to assess prevalence of Dental Phobia. Dentistry 8: 491. doi:10.4172/2161-1122.1000491

Page 4 of 5

\begin{tabular}{|c|c|c|c|c|c|}
\hline \multicolumn{6}{|c|}{ Correlations } \\
\hline \multicolumn{2}{|c|}{ Spearman's rho } & Seeing the needle & Feeling the injection & LA injection & Anxiety score \\
\hline \multirow{3}{*}{ Seeing the needle } & Correlation coefficient & 1.000 & $.771^{\star \star}$ & $.488^{* \star}$ & $.524^{* *}$ \\
\hline & Sig. (2-tailed) & . & .000 & .000 & .000 \\
\hline & $\mathrm{N}$ & 180 & 180 & 180 & 180 \\
\hline \multirow{3}{*}{ Feeling the injection } & Correlation coefficient & $.771^{* *}$ & 1 & $.644^{* *}$ & $.530^{\star *}$ \\
\hline & Sig. (2-tailed) & .000 & . & .000 & .000 \\
\hline & $\mathrm{N}$ & 180 & 180 & 180 & 180 \\
\hline \multirow{3}{*}{ LA injection } & Correlation coefficient & $.488^{* *}$ & $.644^{\star *}$ & 1.000 & $.756^{\star *}$ \\
\hline & Sig. (2-tailed) & .000 & .000 & . & .000 \\
\hline & $\mathrm{N}$ & 180 & 180 & 180 & 180 \\
\hline \multirow{3}{*}{ Anxiety score } & Correlation coefficient & $.524^{* *}$ & $.530^{* *}$ & $.756^{\star *}$ & 1.000 \\
\hline & Sig. (2-tailed) & .000 & .000 & .000 & . \\
\hline & $\mathrm{N}$ & 180 & 180 & 180 & 180 \\
\hline
\end{tabular}

Table 4: Spearman's rank correlation test.

\begin{tabular}{|c|c|c|c|c|c|}
\hline \multicolumn{4}{|c|}{} & \multicolumn{3}{c|}{ Group statistics } \\
\hline \multirow{3}{*}{ VAS Vibraject } & Groups & N & Mean & Std. deviation \\
\cline { 2 - 5 } & Vibraject & 31 & 1.6774 & 1.27507 \\
\cline { 2 - 5 } & Conventional & 29 & 4.4828 & 2.24596 \\
\hline
\end{tabular}

Table 5: VAS comparison between conventional and vibraject.

\begin{tabular}{|c|c|c|c|c|c|c|c|c|c|}
\hline \multicolumn{10}{|c|}{ Independent samples test } \\
\hline \multirow[b]{3}{*}{ VAS Vibraject } & \multicolumn{2}{|c|}{$\begin{array}{l}\text { Levene's test for } \\
\text { equality of variances }\end{array}$} & \multicolumn{7}{|c|}{ T-test for equality of means } \\
\hline & \multirow{2}{*}{$\mathrm{F}$} & \multirow{2}{*}{ Sig. } & \multirow{2}{*}{$\mathrm{t}$} & \multirow{2}{*}{$d f$} & \multirow{2}{*}{ P VALUE } & \multirow{2}{*}{ Mean Difference } & \multirow{2}{*}{ Std. Error Difference } & \multicolumn{2}{|c|}{$95 \%$ Confidence Interval of the Difference } \\
\hline & & & & & & & & Lower & Upper \\
\hline Equal variances assumed & 10.694 & .002 & -5.999 & 58 & 0.00001 & -2.80534 & 0.46760 & -3.74135 & -1.86933 \\
\hline Equal variances not assumed & & & -5.896 & 43.720 & .000 & -2.80534 & 0.47580 & -3.76443 & -1.84625 \\
\hline
\end{tabular}

Table 6: t- Test results.

during insertion of needle and during deposition of solution when compared to the conventional injection technique. Evaluation of the objective signs of pain including BP and Pulse at T0, T1, T2 showed that in conventional technique, the change in the $\mathrm{BP}$ at $\mathrm{T} 0-\mathrm{T} 1$ was 12 $20 \mathrm{mmHg}$ and T0-T2 showed a reduction in the systolic pressure by an average of $10 \mathrm{~mm}$ of $\mathrm{Hg}$ with the change in the Pulse rate being 15-20 bpm between T0 ANS T1. This change was higher compared to the study group which had an average change of T0- T1 6-8 $\mathrm{mm}$ of BP and Pulse of $10 \mathrm{bpm}$ T0-T1 Pulse however, this was not statistically significant (Table 6).

\section{Discussion}

Pain is one of the primary factors that drives the patient to seek dental treatment. The dental anxiety associated with anticipation of the treatment procedures synergistically acts in favor of pain making pain control- anesthesia extremely challenging in these patients (Table 3). Current scientific literature provides evidence that the body-self is a wide spread of neurons between the thalamus and cortex and between the cortex and limbic system where repeated cyclical processing and synthesis of nerve impulses through the neuromatrix imparts to a characteristic pattern to every stimulus: the neurosignature [5]. All inputs from the body undergo this cyclical processing and synthesis, so that characteristic patterns are imprinted in the neuromatrix with pain being no different. The memory of these neurosignatory patterns is engrained in the hippocampus formation which induces anxiety for the procedure and prepares the body for the prime behavioural responses of flight or fight [6]. This is evident in the form of autonomic response of the body to pain in the form of increase Heart Rate (HR) and BP. Thus to achieve successful pain control, both the limbs of painPerception and Response need to be adequately modulated [7] and the success of anesthesia can therefore be assessed by achieving stability of these autonomic responses.

The first part of the current study tried to evaluate the demographic pattern of dental anxiety and the cause of the same. The results of our study results are similar to the other studies in view of the fact that the dental anxiety is more common in women of the middle age group than the men and trypanophobia (Phobia to needle prick) is the primary cause of dental anxiety followed by the fear of the use of the dental drills. Evaluation of the cause of fear considering the 4 dimensions factors associated with injection of LA revealed that the needle prick is the prime anxiety factor compared to the fear associated with adverse reactions to the anesthetic, spread of contagious diseases. Considering the foresaid factors, it is essential to have a pain free, operator friendly simple anesthetic armamentarium for intra oral LA injections that improve patient comfort and alleviate their anxiety.

Various novel pharmacologic and non-pharmacologic methods are currently being used to overcome trypanophobia. C-CLAD device, Intraosseous (IO) system and Wand are the novel armamentarium that have been added to the existing armamentarium to overcome the issues of trypanophobia [8]. However these techniques few studies have shown that this drug delivery system may cause tissue blanching [9-11]. 
Other than this, C-CLAD is also expensive and technique sensitive and is not easily available for regular usage. IO system and STA/Wand have restricted application in the field of oral and maxillofacial surgery due to their localized site of action and may warrant multiple needle pricks when quadrant dentistry is followed.

Various pharmacologic and non-pharmacologic anxiolytic methods have been applied in the past to reduce the dental anxiety in patients undergoing dental treatment including pre emptive use of anxiolytic drugs, conscious sedation, psychological training by distraction methods like the use of music analgesia, bio feedback. However these methods have shown variable success rates in clinical practice and need special multi parameter monitors to monitor the depth of anxiolysis/ sedation. Sometimes these procedures may also warrant prior hospital admission though done on a day care basis.

Vibraject is a novel advancement in the field of dental anesthesia that has gained significant value in present dental care settings to achieve pain free anesthesia. Vibraject is a power operated vibratory device that can be clipped onto the conventional syringe to induce vibrations. These vibrations are transmitted from the barrel of the syringe to the needle. The patient perceives these vibrations at the time of needle prick which make the nociceptive impulses associated with needle prick imperceptible. This mechanism can be well explained by the gate control theory of Melzack and Wall which states that the Substantia gelatinosa acts as a gating site to the impulses that it receives [5]. The sensation of the vibrations is transmitted by larger and faster A beta fibres as compared to the pain sensation that is transmitted by the relatively narrower/relatively slower A Delta and C fibres. The Substantia gelatinosa of the spinal cord facilitates the transmission of the rapidly discharging larger vibratory neuronal fibres thus the patient perceives the sensation of vibration instead of pain at the time of the needle prick. The success of this armamentarium was evident in the form of reduced VAS scores with the use of Vibraject compared to the conventional technique. However, objective evaluation of the autonomic responses in the form of HR and BP did reveal an increased HR and systemic pressure in both the groups. This can be attributed to the fact that though the pain induction process (Needle prick) is perceived as vibration, the anxiety of trypanophobia and visual stimulus of needle activates the hippocampal memory preparing the body for the negative behavioral response causing an increase in HR and systolic BP. Yoshikawa et al. found no significant pain reduction when Vibraject was applied with a conventional dental syringe [12]. In similar study in Chennai, Vibraject has significantly reduced pain both during insertion of needle and during deposition of solution when compared to the conventional injection technique [13]. In a study done in United States having comparing wand with vibraject, there was no statistical difference in the pain perceived by a dental patient when injected using the Vibraject as opposed to injecting with the wand [14]. Based on a study in Tokyo the effect of Vibraject on pain reduction is insufficient and that topical anesthesia may still be required [15]. Syringe micro vibrator and vibraject are designed to alleviate the injection pain during anesthesia injections. There has been no significant difference in pain perception in patients with a higher pain tolerance [16].

The results of our study consistently reveals that patients perceive vibraject to be less invasive and less painful compared to the conventional injection method and can be advocated for regular dental practice. However it has to be practiced on a regular basis in order to condition the patients and alleviate trypanophobia.

\section{References}

1. Armfield $\mathrm{J}$ (2012) The avoidance and delaying of dental visits in Australia Australian Dental Journal 57: 243-247.

2. Humphris GM, Freeman R, Campbell J, Tuutti H, D'Souza V (2000) Further evidence for the reliability and validity of the Modified Dental Anxiety Scale. Int Dent J 50: 367-370.

3. Kleinknecht RA, Thorndike RM, McGlynn FD, Harkavy J (1939) Factor analysis of the dental fear survey with cross-validation. J Am Dent Assoc 108: 59-61.

4. Ali FM, Bai P, Dungrani H, Raju MV, Ustad F, et al. (2015) Nature and prevalence of needle phobia among dental college patients. J Dent Res Rev 2: 130-133.

5. Melzack R, Katz J (2004) The Gate Control Theory: Reaching for the Brain In: Craig KD, Hadjistavropoulos T (eds.) Pain: Psychological Perspectives. Mahwah NJ, US: Lawrence Erlbaum Associates, Publishers, pp. 13-34.

6. Ploghaus A, Narain C, Beckmann CF, Clare S, Bantick S, et al. (2001) Exacerbation of pain by anxiety is associated with activity in a hippocampal network. J Neurosci 21: 9896-9903.

7. Nathan PW, Rudge P (1974) Testing the gate-control theory of pain in man. $J$ Neurol Neurosurg Psychiatry 37: 1366-1372.

8. Shane SM, Kessler S (1967) Electricity for sedation in dentistry. J Am Dent Assoc 75: 1369-1375.

9. Gibson RS, Allen KD, Hutfless S, Beiraghi S (1999) The wand vs. traditional injection: A comparison of pain related behaviors. Pediatr Dent 22: 458-462.

10. Friedman MJ, Hochman MN (1997) A $21^{\text {st }}$ century computerized injection system for local pain control. Compend Contin Educ Dent 18: 995-1004.

11. Friedman MJ, Hochman MN (1998) The AMSA injection: a new concept for local anesthesia of maxillary teeth using a computer controlled injection system. Quintessence Int 29: 297-303.

12. Yoshikawa F, Ushito D, Ohe D, Shirasishi Y, Fukayama $H$, et al. (2003) Vibrating dental local anesthesia attachment to reduce injection pain. J Japan Dent Soc Anesthesiol 31: 194-195.

13. Chandrasekaran J, Prabu D, Silviya, Sunayana M, Ahmed A, et al. (2014) Efficacy of painless injection technique-Vibraject-Clinical trial in Chennai, India. International Journal of Medical and Dental Sciences 3: 250-256.

14. Quarnstrom F (2006) Vibraject VS. The Wand for the control of injection pain.

15. Saijo M, Ito E, Ichinohe T, Kaneko Y (2005) Lack of Pain Reduction by a Vibrating Local Anesthetic Attachment: A Pilot Study. Anesth Prog 52: 62-64.

16. Blair J (2002) Vibraject from ITL dental. Dent Econ 92.12: 90. 